\title{
Moderators of the response to a nurse-led psychosocial intervention to reduce depressive symptoms in head and neck cancer patients
}

\author{
Ingeborg C. van der Meulen • Anne M. May • J. Rob. J. de Leeuw • \\ Ron Koole • Miriam Oosterom • Gert-Jan Hordijk • Wynand J. G. Ros
}

Received: 16 July 2014 / Accepted: 5 January 2015 / Published online: 23 January 2015

(C) The Author(s) 2015. This article is published with open access at Springerlink.com

\begin{abstract}
Purpose Little is known about the variables that moderate the response to psychosocial interventions to decrease depressive symptoms in cancer patients. The purpose of this study was to determine whether variables associated with depressive symptoms in cancer patients in general moderate the response to a nurse-led psychosocial intervention in patients with head and neck cancer.

Methods This study is a secondary analysis of a randomized controlled trial evaluating the effect of the nurse counseling and after intervention (NUCAI) on depressive symptoms 12 months after cancer treatment in patients with head and neck cancer. Of 205 patients, 103 received the NUCAI and 102 care as usual. Twenty-one variables were selected for analysis and a linear regression analyses including interaction terms was performed for each variable separately. Significant moderators were post hoc probed.

Results Four moderators were found: marital status, global quality of life, emotional functioning, and social functioning. Patients who were married/living together or had low scores for global quality of life, and emotional or social functioning at baseline benefited more from the NUCAI than patients who were single or with high scores for global quality of life and emotional or social functioning.
\end{abstract}

I. C. van der Meulen • A. M. May · J. R. J. de Leeuw •

M. Oosterom • W. J. G. Ros

Julius Center for Health Sciences and Primary Care, University

Medical Center Utrecht, Str. 6.131, Po Box: 85500, 3508, GA

Utrecht, The Netherlands

I. C. van der Meulen $(\bowtie) \cdot$ R. Koole $\cdot$ G.-J. Hordijk

Departments of Oral Maxillofacial Surgery and

Otorhinolaryngology, University Medical Center Utrecht, G05.129,

PO Box: 85500, 3508GA Utrecht, The Netherlands

e-mail: i.c.vandermeulen@umcutrecht.nl
Conclusions Marital status, global quality of life, and emotional and social functioning of head and neck cancer patients should be evaluated to determine whether they might benefit from a psychosocial intervention to combat depressive symptoms. Further research is necessary to replicate results and to contribute to the knowledge needed to make screening and personalized patient care possible.

Keywords Psychosocial intervention · Moderators · Head and neck cancer · Depressive symptoms . Health related quality of life

\section{Introduction}

Head and neck cancer is the sixth most common cancer worldwide [1] with approximately 690,000 new cases annually worldwide, which accounts for $4.9 \%$ of the total cancer incidence [2]. Patients diagnosed with head and neck cancer face unique challenges, because the effects of the cancer and its treatment are in many cases visible and have a strong negative impact on diverse functions. Impaired speech, drooling, difficulty chewing, and altered facial appearance are just a few examples, and these changes can influence social interactions and alter patients' self-esteem [3]. In addition, of the patients recently diagnosed with head and neck cancer $28-29 \%$ is experiencing depressive symptoms [4], which is $28-39 \%$ after 6 months $[4,5]$ and $20 \%$ at 1 year after treatment [6]. Several interventions have proven effective in decreasing depressive symptoms in these patients [7-11]. We recently found that the nurse counseling and after intervention (NUCAI), a psychosocial intervention, effectively decreased depressive symptoms 1 year after treatment of head and neck cancer 
[11]. Although this intervention is currently offered to all patients, it might not be effective in some patients. In order to gain more insight into which patients might benefit from the intervention, knowledge is needed of the variables that moderate the effect of the intervention [12].

A recent systematic review [13] identified 14 significant variables that moderate the outcomes of interventions in patients with cancer. For example, patients with a poor global quality of life $(\mathrm{QoL})$, poor interpersonal relationships, and high emotional expressiveness appeared to benefit more than other patients. However, the review included a rather broad range of interventions, such as psychosocial, psycho-educational, and mind-body interventions aiming to increase psychosocial well-being. Less is known about which variables moderate depressive symptoms in patients with head and neck cancer. In a literature search, we found younger age [14, 15], female gender [16], lower educational level [17, 18], living alone and unemployment [19], higher tumor stage [14, 20], adjuvant chemotherapy [16], smoking and daily drinking [17], avoidance and helpless coping [4, 21, 22], lower social support [23, 24], lower global QoL [15, 19, 25, 26], lower physical functioning [27], lower emotional functioning [28], lower social functioning [27], higher level of pain [29, 30], more intrusive thoughts [31], lower self-esteem [32], and lower self-efficacy $[32,33]$ to influence depressive symptoms in patients with cancer. The purpose of the current study was to investigate whether these variables, which are associated with depressive symptoms in cancer patients, moderate the response to a nurse-led psychosocial intervention [11] for the treatment of depressive symptoms in head and neck cancer patients.

\section{Materials and methods}

This study is a secondary analysis of a randomized controlled trial (RCT) evaluating the effect of the NUCAI, a psychosocial intervention, in patients with head and neck cancer (registration number ISRCTN06768231). Newly diagnosed patients were randomly allocated to an intervention or control group. Patients in the control group received care as usual, which consists of a 10-min medical checkup by a specialist in head and neck cancer in the outpatient clinic every 2 months during the first year after cancer treatment. In addition to care as usual, patients in the intervention group received the NUCAI, which consists of six counseling sessions of $60 \mathrm{~min}$ during the first year after cancer treatment, given by a trained nurse. The 2-monthly sessions were combined with the medical checkup. Participants completed seven questionnaires at home, before the start of cancer treatment which is considered as baseline measurement, and at 3, 6, 9, 12, 18, and 24 months after cancer treatment. The primary endpoint was depressive symptoms 12 months after completion of cancer treatment; the other measurements were taken to gain insight into the pattern of change in depressive and health-related QoL variables.

Results showed that the NUCAI decreased depressive symptoms and improved physical functioning, emotional functioning, and pain 12 months after the completion of cancer treatment [11]. More details and other, long-term findings are previously published elsewhere [11, 34].

\section{Patients}

Participants were recruited between January 2005 and September 2007 from the outpatient oral maxillofacial and the otorhinolaryngology clinics of a Dutch university hospital before the start of cancer treatment. Eligibility criteria were a primary diagnosis of squamous cell carcinoma of the oral cavity, oropharynx, hypopharynx, or larynx; treatment with curative intent; ability to complete questionnaires; and ability to participate in the intervention. Patients were excluded if they had a previous or concomitant malignancy and/or were being treated for depression at time of enrollment or before. Depression was diagnosed according to Diagnostic and Statistical Manual of Mental Disorders [35], as stated in the patients' medical record. Note that patients without ongoing treatment for depression were eligible for the trial. After completion of cancer treatment, participants were randomized to the intervention or control group, stratified by gender and tumor stage. Of the 328 eligible patients $63 \%(n=205)$ agreed to participate, 103 participants in the intervention group and 102 participants in the control group. At 12 months, 28 participants were lost to follow-up in the intervention group and 27 participants in the control group. Mean reasons were death ( $n=16$ in intervention group, $n=17$ in control group) and being terminally ill ( $n=4$ in intervention group, $n=2$ in control group). A total of 146 participants had complete data for analyses. The study was approved by the Medical Ethics Committee of the University Medical Centre Utrecht. Eligible patients received verbal and written information about the study, and all participants provided written informed consent.

\section{Measures}

Sociodemographic, disease-related, and treatment-related variables Information on age (continuous), gender (male, female), education level (low (i.e., elementary and lower vocational education), middle (i.e., secondary and secondary vocational education), high (i.e., higher vocational and university education), marital status (married/living together, single), employment status (employed, not employed, retired), smoking (yes, no), and daily drinking $(<3$ units alcohol a day, $>3$ units alcohol a day) was collected by means of self-report questionnaires. Information about type of cancer 
(oral cavity/oropharynx, hypopharynx/larynx), tumor stage (I-II, III-IV), and treatment (surgery, radiotherapy, chemoradiation, combination) was obtained from medical records.

Depressive symptoms Depressive symptoms were measured with the CES-D [36]. This 20-item self-report questionnaire gives a total score ranging from 0 to 60 . A high score reflects a high level of depression. The CES-D has shown good psychometric properties in Dutch patients with head and neck cancer [4].

Health-related quality of life (HRQoL) Global QoL, physical functioning, role functioning, emotional functioning, cognitive functioning, and social functioning were assessed with the EORTC QLQ-C30 version 3.0 [37] and pain with the head and neck module QLQ H\&N35 [38]. A range of 0-100 is used and a high score reflects a high level of functioning or a high level of pain. Both are widely used and have good psychometric properties in patients with head and neck cancer $[38,39]$.

Coping strategy Coping was assessed with the shortened Dutch version of the Coping Inventory for Stressful Situations (CISS) [40]. This 21-item self-report questionnaire measures three dimensions of coping: task-oriented, emotionoriented, and avoidance-oriented coping. Item scores range from 1 (not at all) to 5 (very often). A higher score on each dimension reflects a higher probability of using that coping strategy. The CISS demonstrated good psychometric properties in Dutch patient with internal diseases [41].Chronbach's alpha in the present sample was 0.83 for the task-oriented scale, 0.83 for the emotion-oriented scale, and 0.71 for the avoidance-oriented scale.

Social support Social support was measured with the short version of the Social Support List - Interactions (SSL 12-I) [42]. This questionnaire assesses the extent of perceived received social support by means of social interactions with members of the primary social network. It consists of 12 items with possible item scores ranging from 1 (seldom or never) to 4 (very often) with a higher score reflecting more social support. The SSL 12-I has shown good psychometric properties in Dutch elderly [42] and Dutch patients with rheumatoid arthritis [43]. Chronbach's alpha in the present sample was 0.91 .

\section{Potential moderators}

The following variables were entered in the analyses: age, gender, educational level, marital status, employment status, tumor stage, type of treatment, smoking, daily drinking, task coping, emotion coping, avoidance coping; social support, global QoL, physical functioning, emotional functioning, social functioning, and pain. These variables have been reported in the literature to be associated with depressive symptoms. We additionally included the variables assessed in the NUCAI study, namely, head and neck cancer specific tumor site, role functioning and cognitive functioning, even though there is no evidence in the literature that these variables have a moderating effect. The variables intrusive thoughts, self-esteem, and self-efficacy, which showed to be associated with depressive symptoms, could not be included in the moderator analyses because we did not collect these variables in the NUCAI study. Overall, 21 variables were selected for analysis.

\section{Statistics}

To determine whether there were differences in potential moderators between the intervention and control groups, we performed $t$-tests for continuous variables and $X^{2}$ tests for categorical variables. The variance of the residuals was tested by a scatterplot to examine homoscedasticity and linearity. A linear regression analysis was performed for each moderator separately to identify whether the selected variable moderated the effect of the intervention on depressive symptoms at 12 months after cancer treatment. Continuous potential moderators were centered to reduce multicollinearity, and for the categorical potential moderators, educational level, employment status, and type of treatment, dummies were created. The first category was used as reference. The linear regression model contained the continuous depressive symptom score at 12 months as dependent variable. Group (intervention versus control), the centered potential moderator at baseline, the group by moderator interaction, and the centered continuous baseline depressive symptoms score were entered as independent variables. All participants who completed the baseline and the 12-month assessments were included in the full-case analyses.

In addition to the full-case, an intention to treat analyses was performed. Participants who did not complete the 12month assessment but who minimally completed the baseline and 3-month assessments were included. To determine whether there were differences in potential moderators between the participants in the full-case analyses and the additional participants who entered the intention-to-treat analyses, $t$-tests were performed for continuous variables and $X^{2}$ tests for categorical variables. Missing values were imputed in the intention-totreat sample. Multiple imputation $(10 \times)$ was carried out for missing 12 months post-cancer treatment score for depressive symptoms as well as missing baseline scores of, coping strategy, social support, cognitive functioning, and depressive symptoms. Constraints were given for each variable. All other variables were used as indicator.

The linear regression analyses were repeated and the pooled outcome of the 10 imputation datasets was used as result. 
Table 1 Participant characteristics at baseline

\begin{tabular}{|c|c|c|c|c|}
\hline & \multicolumn{2}{|c|}{ Full-case analyses, $n=146^{\mathrm{a}}$} & \multicolumn{2}{|c|}{ Intention-to-treat analyses, $n=179^{\mathrm{a}}$} \\
\hline & $\begin{array}{l}\text { Intervention group } \\
(n=73)\end{array}$ & $\begin{array}{l}\text { Control group } \\
(n=73)\end{array}$ & $\begin{array}{l}\text { Intervention group } \\
(n=88)\end{array}$ & $\begin{array}{l}\text { Control group } \\
(n=91)\end{array}$ \\
\hline \multicolumn{5}{|l|}{ Age } \\
\hline Years (mean (SD)) & $59.5(8)$ & $59.9(9)$ & $60.1(10)$ & $60.7(10)$ \\
\hline \multicolumn{5}{|l|}{ Gender (no. (\%)) } \\
\hline Male & $53(73)$ & $55(75)$ & $62(70)$ & $64(70)$ \\
\hline Female & $20(27)$ & $18(25)$ & $26(30)$ & $27(30)$ \\
\hline \multicolumn{5}{|l|}{ Educational level (no. (\%)) } \\
\hline Low & $32(44)$ & $33(45)$ & $37(42)$ & $37(41)$ \\
\hline Middle & $26(36)$ & $29(40)$ & $32(36)$ & $41(45)$ \\
\hline High & $15(21)$ & $11(15)$ & $19(22)$ & $13(14)$ \\
\hline \multicolumn{5}{|l|}{ Marital status (no. (\%)) } \\
\hline Married/living together & $54(74)$ & $53(73)$ & $63(71.6)$ & $67(74)$ \\
\hline Single & $19(26)$ & $20(27)$ & $25(28.4)$ & $24(26)$ \\
\hline \multicolumn{5}{|l|}{ Employment status (no. (\%)) } \\
\hline Employed & $25(34)$ & $30(41)$ & $31(35)$ & $34(37)$ \\
\hline Not employed & $23(32)$ & $25(34)$ & $29(33)$ & $34(37)$ \\
\hline Retired & $16(22)$ & $17(23)$ & $19(22)$ & $21(23)$ \\
\hline Unknown & $9(12)$ & $1(1)$ & $9(10)$ & $2(2)$ \\
\hline \multicolumn{5}{|l|}{ Tumor site (no. (\%)) } \\
\hline Oral cavity and oropharynx & $46(63)$ & $48(66)$ & $57(65)$ & $61(67)$ \\
\hline Hypopharynx and larynx & $27(37)$ & $25(34)$ & $31(35)$ & $29(32)$ \\
\hline Unknown primary & - & - & - & $1(1)$ \\
\hline \multicolumn{5}{|l|}{ Tumor stage $^{\mathrm{b}}($ no. $(\%))$} \\
\hline I-II & $43(59)$ & $47(64)$ & $51(58)$ & $55(60)$ \\
\hline III-IV & $30(41)$ & $26(36)$ & $37(42)$ & $36(40)$ \\
\hline \multicolumn{5}{|l|}{ Type of treatment (no. (\%)) } \\
\hline Surgery & $17(23)$ & $26(36)$ & $22(25)$ & $29(32)$ \\
\hline Radiotherapy & $21(29)$ & $21(29)$ & $25(28)$ & $24(26)$ \\
\hline Chemoradiation & $11(15)$ & $8(11)$ & $12(14)$ & $12(13)$ \\
\hline Combination & $24(33)$ & $18(25)$ & $29(33)$ & $26(29)$ \\
\hline \multicolumn{5}{|l|}{ Smoking (no. $(\%)$ ) } \\
\hline Yes & $29(40)$ & $33(45)$ & $33(38)$ & $37(41)$ \\
\hline No & $44(60)$ & $40(55)$ & $55(63)$ & $54(59)$ \\
\hline \multicolumn{5}{|l|}{ Daily drinking (no. (\%)) } \\
\hline Yes & $26(36)$ & $22(30)$ & $27(31)$ & $27(30)$ \\
\hline No & $47(64)$ & $51(70)$ & $61(69)$ & $64(70)$ \\
\hline \multicolumn{5}{|l|}{ Coping strategy (mean (SD) $)^{\mathrm{c}, \mathrm{d}}$} \\
\hline Task oriented & $18(6)$ & $18(5)$ & $18(6)$ & $17(5)$ \\
\hline Emotion oriented & $12(5)$ & $13(5)$ & $12(5)$ & $13(5)$ \\
\hline Avoidance & $12(5)$ & $12(3)$ & $12(5)$ & $12(3)$ \\
\hline Social support $(\text { mean }(\mathrm{SD}))^{\mathrm{c}, \mathrm{d}}$ & $2.9(0.6)$ & $2.6(0.5)$ & $2.9(0.6)$ & $2.7(0.5)$ \\
\hline Global quality of life (mean (SD)) & $68(23)$ & $68(22)$ & $67(23)$ & $66(23)$ \\
\hline Physical functioning (mean (SD)) & $84(19)$ & $88(16)$ & $84(16)$ & $87(18)$ \\
\hline Role functioning (mean (SD)) & $76(28)$ & $78(29)$ & $76(28)$ & $78(29)$ \\
\hline Emotional functioning (mean (SD)) & $64(25)$ & $67(25)$ & $65(25)$ & $67(23)$ \\
\hline Cognitive functioning (mean (SD) $)^{\mathrm{d}}$ & $82(22)$ & $85(21)$ & $84(22)$ & $84(22)$ \\
\hline Social functioning (mean (SD)) & $82(23)$ & $84(21)$ & $83(22)$ & $83(21)$ \\
\hline
\end{tabular}


Table 1 (continued)

\begin{tabular}{|c|c|c|c|c|}
\hline & \multicolumn{2}{|c|}{ Full-case analyses, $n=146^{\mathrm{a}}$} & \multicolumn{2}{|c|}{ Intention-to-treat analyses, $n=179^{\mathrm{a}}$} \\
\hline & $\begin{array}{l}\text { Intervention group } \\
(n=73)\end{array}$ & $\begin{array}{l}\text { Control group } \\
(n=73)\end{array}$ & $\begin{array}{l}\text { Intervention group } \\
(n=88)\end{array}$ & $\begin{array}{l}\text { Control group } \\
(n=91)\end{array}$ \\
\hline Pain (mean (SD)) & $35(26)$ & $32(25)$ & $36(26)$ & $31(24)$ \\
\hline Depressive symptoms (mean (SD) $)^{\mathrm{d}}$ & $12(9)$ & $13(11)$ & $13(9)$ & $13(10)$ \\
\hline
\end{tabular}

$S D$ standard deviation

${ }^{a}$ Data is given of participants who completed a minimum of two measurements $(n=179)$

${ }^{\mathrm{b}}$ Tumor stage according to the TNM Classification of Malignant Tumors

${ }^{\mathrm{c}}$ Incomplete baseline data for participants in full-case analyses: task-oriented coping $(n=129)$, emotion-oriented coping $(n=131)$, avoidance coping $(n=$ 132), and social support $(n=137)$

${ }^{\mathrm{d}}$ Incomplete baseline data for participants in intention-to-treat analyses: task-oriented coping $(n=154)$, emotion-oriented coping ( $\left.n=157\right)$, avoidance coping $(n=159)$, social support $(n=165)$, cognitive functioning $(n=178)$ and depressive symptoms $(n=178)$

Effect sizes (ES) were calculated for each regression model in order to estimate the variance explained by the interaction term. Therefore, the proportion of variance accounted for in the model with the interaction term was subtracted from the model without the interaction term. Cohen's [44] cutoff points were used to indicate a small $(\mathrm{ES}=0.02)$, medium $(\mathrm{ES}=0.15)$, or large ( $E S=0.35)$ effect. In addition, the achieved power for each regression model was calculated using the statistical software of $\mathrm{G}^{*}$ Power [45].

Finally, the significant moderators were post hoc probed to determine if the relation between depressive symptom and group (intervention vs control) is significant for the categories of the moderators. For the continuous moderators the categories $-1 \mathrm{SD}$, mean, and $+1 \mathrm{SD}$ score were generated. For categorical moderators, the existing categories were used. The statistical software PROCESS of A. Hayes [46] was used for the post hoc probing analyses.

All analyses were, unless otherwise stated, performed using SPSS version 21. Statistical significance was set at $p<0.05$ (two-tailed).

\section{Results}

Baseline characteristics

In total, 103 participants were randomized to the intervention group and 102 to the control group. A minimum of two assessments were available for 88 participants in the intervention group and 91 participants in the control group (intentionto-treat analyses), and 73 participants in the intervention group and 73 participants in the control group completed the 12 month post-cancer treatment assessment (full-case analyses) (Table 1). The intervention and control groups were similar in terms of sociodemographic, disease-related, and treatmentrelated characteristics and potential moderators. In addition, there were no significant differences between the full-case participants $(n=146)$ and the additional participants who entered the intention-to-treat analyses $(n=33)$ (all $p>0.05)$.

\section{Moderator analyses}

The data was considered to be normally distributed, homoscedastic, and linear for all potential moderators. In the full-case analyses, the linear regression analyses identified four significant moderators: marital status $(b=-6.75, p=0.04)$, global QoL $(b=-0.14, p=0.03)$, emotional functioning $(b=-0.14$, $p=0.02)$, and social functioning $(b=-0.13, p=0.04)$ (Table 2). In the intention-to-treat analyses, emotional functioning ( $b=-0.14, p=0.02)$ and social functioning $(b=-0.15$, $p=0.03$ ) were identified as moderators. A trend to significance was found for marital status $(b=-5.96, p=0.08)$ and global QoL $(b=-0.14, p=0.05)$ (Table 2).

Effect sizes ranged from 0.00 to 0.25 and achieved power from 0.05 to 0.56 for gender in the full-case analyses and emotional functioning in the intention-to-treat analyses, respectively (Table 2). Post hoc probing analyses revealed a significant group difference in marital status in favor of patients who were married or living together $(b=-4.25, p=0.01)$ compared to patients who were single. Furthermore, patients with low ( $-1 \mathrm{SD})$ baseline scores on global QoL $(b=-5.65$, $p=0.01$ ), emotional functioning $(b=-5.99, p=0.00)$, and social functioning $(b=-5.41, p=0.01)$ differed significantly from patients with mean or high $(+1 \mathrm{SD})$ baseline scores (Table 3). This indicates that patients who were married or living together, and patients with low baseline scores on global QoL, emotional functioning, and social functioning responded better to the NUCAI than patients who were single or had mean or high baseline scores. Regression lines for each relationship between group (control vs NUCAI) and depressive symptom score at 12 months post-cancer treatment as moderated by marital status, global QoL, emotional functioning, or social functioning are given in Fig. 1. 
Age, gender, educational level, employment status, tumor stage, type of treatment, smoking, daily drinking, task coping, emotion coping, avoidance coping, social support, physical functioning, pain, tumor site, role functioning, and cognitive functioning did not moderate the effect of the NUCAI on depressive symptoms 12 months posttreatment.

\section{Discussion}

The present study investigated moderators of the response to a nurse-led psychosocial intervention, the nurse counseling and after intervention (NUCAI). The NUCAI has been found to decrease depressive symptoms 1 year after treatment of head

Table 2 Potential moderators of the intervention effect in full-case analyses and intention-to-treat analyses

\begin{tabular}{|c|c|c|c|c|c|c|c|c|c|c|}
\hline \multirow[b]{3}{*}{ Potential moderators } & \multicolumn{5}{|c|}{$\mathrm{BL}-12 \mathrm{M}$} & \multicolumn{5}{|c|}{$\mathrm{BL}-12 \mathrm{M}$} \\
\hline & \multicolumn{5}{|c|}{ Full case analyses $(n=146)$} & \multicolumn{5}{|c|}{ Intention-to-treat analyses $(n=179)$} \\
\hline & $p$ & $95 \%$ CI & Unstand. $\beta$ & $\mathrm{ES}^{\mathrm{c}}$ & Power & $p$ & $95 \% \mathrm{CI}$ & Unstand. $\beta$ & $\mathrm{ES}^{\mathrm{c}}$ & Power \\
\hline \multicolumn{11}{|c|}{ Sociodemographic, disease-related, and treatment-related variables } \\
\hline Age & 0.28 & -0.51 to 0.15 & -0.18 & 0.005 & 0.14 & 0.55 & -0.48 to 0.26 & -0.11 & 0.005 & 0.16 \\
\hline Gender & 0.79 & -5.51 to 7.23 & 0.68 & 0.000 & 0.05 & 0.69 & -4.94 to 7.50 & 1.28 & 0.001 & 0.07 \\
\hline Education & & & & 0.004 & 0.12 & & & & 0.002 & 0.09 \\
\hline Low vs middle & 0.54 & -8.19 to 4.33 & -1.93 & & & 0.94 & -6.87 to 6.38 & -0.24 & & \\
\hline Low vs high & 0.38 & -11.65 to $4-49$ & -3.58 & & & 0.83 & -9.85 to 7.91 & -0.97 & & \\
\hline Marital status & $0.04 *$ & -13.02 to -0.48 & -6.75 & 0.019 & 0.38 & 0.08 & -12.59 to 0.67 & -5.96 & 0.018 & 0.43 \\
\hline Employment status & & & & 0.016 & 0.31 & & & & 0.013 & 0.31 \\
\hline Employed vs not employed ${ }^{a}$ & 0.11 & -1.22 to 12.11 & 5.45 & & & 0.33 & -3.70 to 10.86 & -3.58 & & \\
\hline Employed vs retired $^{\mathrm{a}}$ & 0.12 & -1.57 to 13.25 & 5.84 & & & 0.21 & -3.06 to 13.59 & 5.27 & & \\
\hline Tumor site & 0.27 & -2.58 to 9.14 & 3.28 & 0.005 & 0.14 & 0.61 & -4.55 to 7.69 & 1.57 & 0.002 & 0.09 \\
\hline TNM status & 0.68 & -4.65 to 7.07 & 1.21 & 0.001 & 0.07 & 0.81 & -5.37 to 6.88 & 0.75 & 0.001 & 0.07 \\
\hline Treatment & & & & 0.006 & 0.15 & & & & 0.002 & 0.09 \\
\hline Surgery vs radiotherapy & 0.26 & -3.14 to 11.73 & 4.30 & & & .83 & -6.92 to 8.68 & 0.88 & & \\
\hline Surgery vs chemoradiation & 0.52 & -6.42 to 12.55 & 3.06 & & & 0.96 & -9.95 to 10.43 & 0.24 & & \\
\hline Surgery vs combination & 0.51 & -5.07 to 10.22 & 2.58 & & & 1.00 & -7.65 to 7.66 & 0.01 & & \\
\hline Smoking & 0.07 & -0.34 to 11.06 & 5.36 & 0.014 & 0.29 & 0.24 & -2.42 to 9.59 & 3.59 & 0.007 & 0.20 \\
\hline Daily drinking & 0.58 & -7.75 to 4.36 & -1.69 & 0.001 & 0.07 & 0.46 & -8.84 to 3.97 & -2.44 & 0.003 & 0.11 \\
\hline \multicolumn{11}{|l|}{ Coping strategy } \\
\hline Task coping ${ }^{\mathrm{b}}$ & 0.97 & -0.52 to 0.55 & 0.01 & 0.000 & 0.05 & 0.92 & -0.55 to 0.49 & -0.03 & 0.001 & 0.07 \\
\hline Emotion coping $^{\mathrm{b}}$ & 0.20 & -0.21 to 0.97 & 0.38 & 0.008 & 0.17 & 0.28 & -0.30 to 1.01 & 0.36 & 0.007 & 0.20 \\
\hline Avoidance coping ${ }^{\mathrm{b}}$ & 0.60 & -0.57 to 0.99 & 0.21 & 0.001 & 0.07 & 0.76 & -0.67 to 0.93 & 0.13 & 0.002 & 0.09 \\
\hline Social support ${ }^{\mathrm{b}}$ & 0.06 & -10.94 to 0.24 & -5.35 & 0.016 & 0.31 & 0.54 & -7.95 to 4.17 & -1.89 & 0.004 & 0.13 \\
\hline \multicolumn{11}{|c|}{ EORTC-QLQ-C30 and H\&N35 variables } \\
\hline Global quality of life & $0.03 *$ & -0.26 to -0.02 & -0.14 & 0.021 & 0.41 & 0.05 & -0.28 to 0.00 & -0.14 & 0.024 & 0.54 \\
\hline Physical functioning & 0.55 & -0.21 to 0.11 & -0.05 & 0.001 & 0.07 & 0.50 & -0.23 to 0.11 & -0.06 & 0.003 & 0.11 \\
\hline Role functioning & 0.24 & -0.16 to 0.04 & -0.06 & 0.005 & 0.14 & 0.26 & -0.16 to 0.05 & -0.06 & 0.007 & 0.20 \\
\hline Emotional functioning & $0.02 *$ & -0.25 to -0.02 & -0.14 & 0.024 & 0.46 & $0.02 *$ & -0.26 to -0.02 & -0.14 & 0.025 & 0.56 \\
\hline Cognitive functioning & 0.18 & -0.22 to 0.04 & -0.09 & 0.007 & 0.17 & 0.32 & -0.20 to 0.07 & -0.07 & 0.004 & 0.13 \\
\hline Social functioning & $0.04 *$ & -0.26 to -0.01 & -0.13 & 0.018 & 0.36 & $0.03 *$ & -0.27 to -0.02 & -0.15 & 0.022 & 0.51 \\
\hline Pain & 0.31 & -0.06 to 0.17 & 0.06 & 0.004 & 0.12 & 0.18 & -0.04 to -0.20 & 0.08 & 0.010 & 0.27 \\
\hline
\end{tabular}

$B L$ baseline measurement, $C I$ confidence interval, Unstand. $\beta$ undstandardized beta, $E S$ effect size

$* p$ value is $<0.05$

${ }^{a}$ Patients whose employment status was unknown were not included in analyses

${ }^{\mathrm{b}}$ Incomplete data in full-case analyses: task-oriented coping ( $\left.n=129\right)$, emotion-oriented coping $(n=131)$, avoidance coping $(n=132)$, and social support $(n=137)$

${ }^{\mathrm{c}}$ Cohen's (1988) cutoff points were used to indicate a small $(\mathrm{ES}=0.02)$, medium $(\mathrm{ES}=0.15)$, or large $(\mathrm{ES}=0.035)$ effect 
Table 3 Post hoc probing of the significant moderators

\begin{tabular}{|c|c|c|c|c|c|}
\hline & & Moderator baseline value & $p$ value & $95 \% \mathrm{CI}$ & $\beta$ value \\
\hline \multirow[t]{2}{*}{ Marital status } & Married/living together & - & $0.01^{*}$ & -7.49 to -1.01 & -4.25 \\
\hline & Single & - & 0.36 & -2.86 to 7.86 & 2.50 \\
\hline \multirow[t]{3}{*}{ Global quality of life } & $-1 \mathrm{SD}$ & 45.52 & $0.01 *$ & -9.61 to -1.70 & -5.65 \\
\hline & Mean & 68.26 & 0.08 & -5.25 to 0.31 & -2.47 \\
\hline & $+1 \mathrm{SD}$ & 91.01 & 0.72 & -3.23 to 4.65 & 0.71 \\
\hline \multirow[t]{3}{*}{ Emotional functioning } & $-1 \mathrm{SD}$ & 40.30 & $0.00^{*}$ & -9.96 to -2.01 & -5.99 \\
\hline & Mean & 65.26 & 0.07 & -5.38 to 0.20 & -2.59 \\
\hline & $+1 \mathrm{SD}$ & 90.22 & 0.69 & -3.12 to 4.73 & 0.80 \\
\hline \multirow[t]{3}{*}{ Social functioning } & $-1 \mathrm{SD}$ & 60.70 & $0.01^{*}$ & -9.39 to -1.44 & -5.41 \\
\hline & Mean & 83.11 & 0.08 & -5.26 to 0.32 & -2.47 \\
\hline & $+1 \mathrm{SD}$ & 100 & 0.89 & -3.75 to 3.25 & -0.25 \\
\hline
\end{tabular}

Analyses were performed in the full-case group $(n=146)$

$C I$ confidence interval, $\beta$ beta, $S D$ standard deviation

$* p$ value is $<0.05$

and neck cancer [11]. In this secondary analysis, we found that patients who were married/living together had low baseline scores on global QoL, emotional functioning, or social functioning benefitted more of the NUCAI, resulting in lower
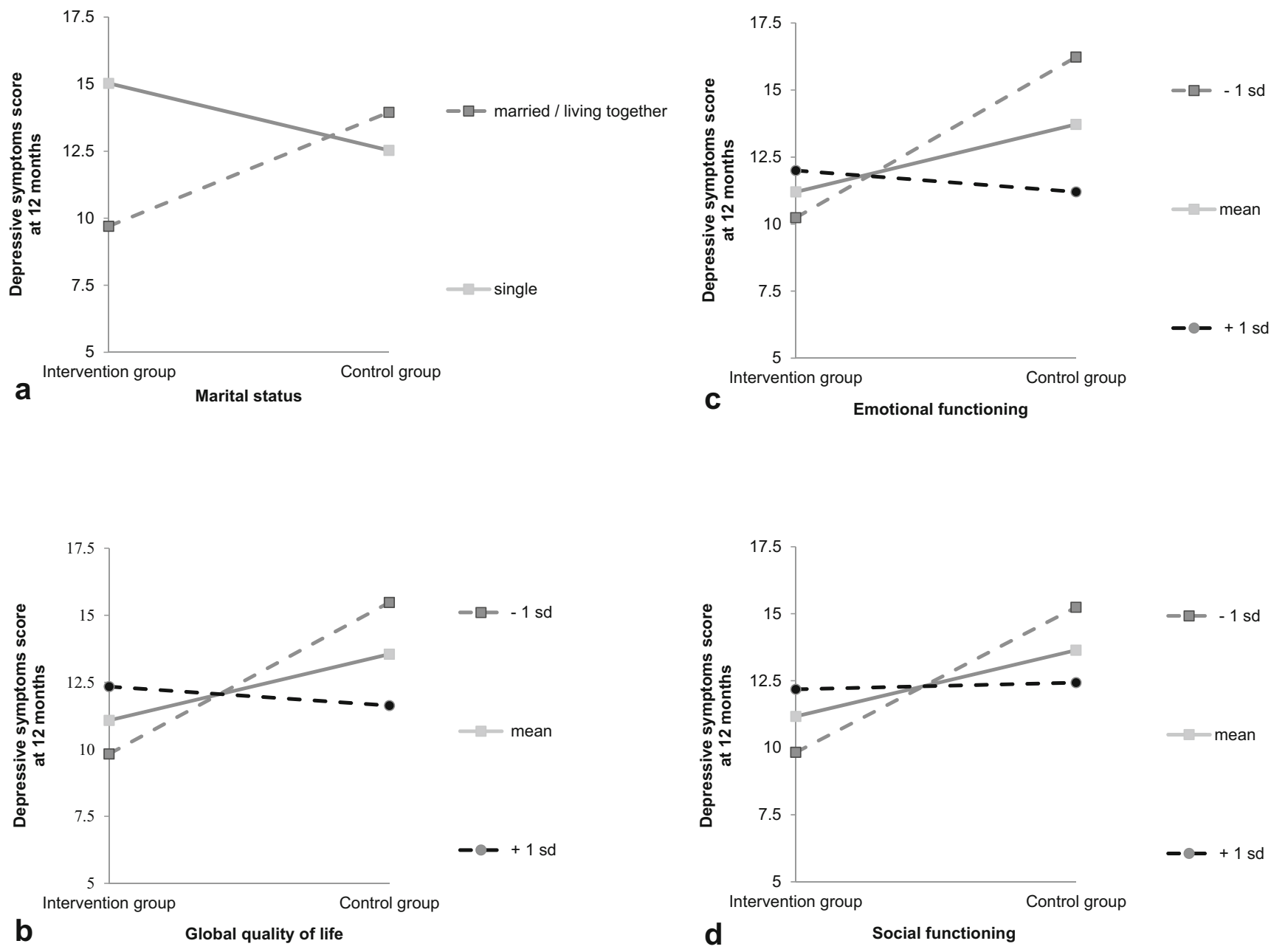

Fig. 1 Regression lines for the relationship between group (intervention vs control) and depressive symptom score at 12 months post-cancer treatment, as moderated by marital status (a), global quality of life (b), emotional functioning (c), or social functioning (d) 
depressive symptom scores 12 months posttreatment, than patients who were single or had mean or high baseline scores on global QoL, emotional functioning or social functioning.

Patients with low baseline scores for emotional functioning showed a statistical significant improvement of almost 6 points on the depressive symptoms scale. Although a minimal clinically important difference of the CES-D is not yet established, we considered this difference as clinical significant, according to Norman et al. who showed that a change of half a standard deviation indicates a clinical relevant difference [47]. Only one study was found in the literature that explored the moderating effect of emotions in patients with cancer. Manne et al. [28] showed, in a large RCT involving women with gynecological cancer, that women who were more expressive of positive emotions benefitted more from a supportive counseling intervention than women who were less expressive of positive emotions. Results for negative emotions were not computed because of the low internal consistency of the data. Our results are inconsistent with those of Manne et al. [28], which could be due to the different types of cancer studied and the gender of the participants (solely women versus $70 \%$ men in our study). In addition, Gamper et al. [49] recently defined emotional functioning as a variable that covers aspects of anxiety, depression, and general distress, which is much broader than expression of emotions alone.

We also found that patients with head and neck cancer who had low scores for social functioning at baseline responded statistically and clinically significantly better, with a decrease of 5.4 points on the depressive symptoms scale, to the NUCAI than patients with high scores for social functioning. Balderson et al. [27] reported that social/family well-being was related to lower psychological distress in patients with prostate cancer, which is in line with our results.

The full-case analyses showed that patients who were married/living together had fewer depressive symptoms (a decrease of 4.3 points) 1 year after cancer treatment than patients who were single and thus benefited more from the NUCAI. The intention-to-treat analyses showed the same trend. It should be mentioned that, with the NUCAI, patients are encouraged to bring their partners to intervention sessions. Mikoshiba et al. [19] found that living alone was associated with an increased likelihood of depressive symptoms in patients with liver cancer. Perhaps if a partner follows the intervention with the patient, he/she can discuss the intervention with the patient at home and might stimulate and support the patient.

A poorer global QoL at baseline was also found to be a moderator of the effect of the NUCAI in both the full-case and intention-to-treat analyses, with patients with a worse global QoL at baseline responding better (a decrease of 6.7 points on the depressive symptoms scale) to treatment than patients with a better global QoL. While we did not find any articles in the literature that expressly investigated this, several studies have shown that higher depressive symptom scores or depression are related to a lower global QoL in cancer patients [19, 25, 26]. Overall, no significant improvements were found for patients who had high $(+1 \mathrm{SD})$ global QoL, emotional functioning, and social functioning scores. The CES-D is found to be sensitive to changes in depressive symptoms after intervention [48]; however, it could be that these patients with high scores had little room to improve and therefore only minor changes in depressive symptoms could be established. This should be considered when offering the NUCAI to patients.

Other studies have shown that social demographic variables (age, gender, educational level, working status), disease-related variables (tumor stage, type of treatment), or health behavior-related variables (smoking, drinking) are related to increased levels of depressive symptoms [13, 14, 16-19]. We did not find these variables to moderate the response to the NUCAI. The NUCAI is patient driven, and it is possible that the nurses personalized the intervention on the basis of these variables, thereby providing a tailored intervention. Overall, there is no evidence at this point that clinical variables should be used when selecting patients with head and neck cancer for a psychosocial intervention. Hence, the NUCAI seems to be of most benefit for head and neck cancer patients who have poor scores on emotional functioning, social functioning, and global QoL. In addition, patients who are single should be given extra attention and should be encouraged to bring a relative or friend to the intervention sessions.

Interestingly, the European Organisation for Research and Treatment of Cancer (EORTC) is developing a computerized adaptive testing measure based on an item bank for, among others, emotional functioning, to be used as a screening tool in cancer patients [49]. This extensive project is in its last phase and seems to be promising for future screening possibilities and could be extended with the other moderators found in this study.

Our findings represent a first step to distinguishing between patients with head and neck cancer who might or might not benefit from a psychosocial intervention. However, the results are secondary analyses and the following limitations should be considered when interpreting outcome. First, this study was not powered for moderator analyses but for the efficacy of the intervention. The effect sizes of the significant moderators varied between 0.018 and 0.024 which is considered to be a small effect [44]. In addition, the power varied between 0.36 and 0.46 which implicate that a larger sample size is needed to detect a relationship between the moderator and the intervention effect without committing a type II error. In addition, because of the explorative nature of the study, the $p$ values were not adjusted for multiple testing. Lastly, not all the variables that are associated with depressive symptoms could be incorporated in the analyses because they were not measured in the NUCAI study. 
In conclusion, little is known about the variables that moderate the response to a psychosocial intervention in head and neck cancer patients. Analyses showed that patients who had poor scores for emotional functioning, social functioning, and global QoL at baseline and who were married or living together benefitted more from the NUCAI than patients with high scores and who were single. We suggest that the screening of patients with head and neck cancer for eligibility for a psychosocial intervention should be based on patients' global QoL, emotional functioning, and social functioning, with extra attention being paid to patients who are single. Because of the explorative nature of this study further, well powered, research is necessary to replicate our results and to provide personalized patient care, so that available resources (time, staff, and money) can be used in the best possible way.

Acknowledgments This research was funded by a grant from the Dutch Cancer Society. We would like to thank Joeri Kalter (EMGO+ Institute, Department of Epidemiology and Biostatistics, VU University Medical Center Amsterdam, The Netherlands) and Rebecca K. Stellato (Julius Center for Health Sciences and Primary Care, University Medical Center Utrecht, the Netherlands) for their guidance on the statistical analyses.

\section{Conflict of interest None}

Open Access This article is distributed under the terms of the Creative Commons Attribution Noncommercial License which permits any noncommercial use, distribution, and reproduction in any medium, provided the original author(s) and the source are credited.

\section{References}

1. Kamangar F, Dores GM, Anderson WF (2006) Patterns of cancer incidence, mortality, and prevalence across five continents: defining priorities to reduce cancer disparities in different geographic regions of the world. J Clin Oncol 24:2137-50. doi:10.1200/JCO.2005.05. 2308

2. Ferlay J, Soerjomataram I, Ervik M, Dikshit K, Eser S, Mathers C et al (2013) GLOBOCAN 2012 v1.0, cancer incidence and mortality worldwide: IARC CancerBase No. 11. International Agency for Research on Cancer, Lyon

3. Taneja MK (2013) Life style management in head and neck cancer patients. Indian J Otolaryngol Head Neck Surg 65:289-92. doi:10. 1007/s12070-013-0682-2

4. de Leeuw JR, de Graeff A, Ros WJ, Hordijk GJ, Blijham GH, Winnubst JA (2000) Negative and positive influences of social support on depression in patients with head and neck cancer: a prospective study. Psychooncology 9:20-8

5. Rogers L, Rao K, Malone J, Kandula P, Ronen O, Markwell S, Courneya K, Robbins KT (2009) Factors associated with quality of life in outpatients with head and neck cancer 6 months after diagnosis. Head Neck 31:1207-1214. doi:10.1002/hed.21084

6. de Leeuw JR, de Graeff A, Ros WJ, Blijham GH, Hordijk GJ, Winnubst JA (2001) Prediction of depression 6 months to 3 years after treatment of head and neck cancer. Head Neck 23:892-898

7. Allison PJ, Edgar L, Nicolau B, Archer J, Black M, Hier M (2004) Results of a feasibility study for a psycho-educational intervention in head and neck cancer. Psychooncology 13:482-485. doi:10.1002/ pon. 816

8. Semple CJ, Dunwoody L, Kernohan WG, McCaughan E (2009) Development and evaluation of a problem-focused psychosocial intervention for patients with head and neck cancer. Support Care Cancer 17:379-388. doi:10.1007/s00520-008-0480-7

9. Sharma D, Nagarkar AN, Jindal P, Kaur R, Gupta AK (2008) Personality changes and the role of counseling in the rehabilitation of patients with laryngeal cancer. Ear Nose Throat J 87:E5-E5

10. Kangas M, Milross C, Taylor A, Bryant RA (2013) A pilot randomized controlled trial of a brief early intervention for reducing posttraumatic stress disorder, anxiety and depressive symptoms in newly diagnosed head and neck cancer patients. Psychooncology 22:16651673. doi: $10.1002 /$ pon. 3208

11. van der Meulen IC, May A, Ros WJG, Oosterom M, Hordijk GJ, Koole R, de Leeuw JRJ (2013) One-year effect of a nurse-led psychosocial intervention on depressive symptoms in patients with head and neck cancer: a randomized controlled trial. Oncologist 18:336344. doi:10.1634/theoncologist. 2012-0299

12. Buffart L, Kalter J, Chinapaw MJM, Heymans M, Aaronson N, Courneya K, Jacobsen P, Newton R, Verdonck-de Leeuw IM, Brug J (2013) Predicting OptimaL cAncer RehabIlitation and Supportive care (POLARIS): rationale and design for meta-analyses of individual patient data of randomized controlled trials that evaluate the effect of physical activity and psychosocial interventions on health-related quality of life in cancer survivors. Systematic Rev 2:75-75. doi:10. 1186/2046-4053-2-75

13. Tamagawa R, Garland S, Vaska M, Carlson L (2012) Who benefits from psychosocial interventions in oncology? A systematic review of psychological moderators of treatment outcome. J Behav Med. doi: 10.1007/s10865-012-9398-0

14. Hammerlid E, Silander E, Hornestam L, Sullivan M (2001) Healthrelated quality of life three years after diagnosis of head and neck cancer-a longitudinal study. Head Neck 23:113-125

15. Reyes-Gibby CC, Anderson KO, Morrow PK, Shete S, Hassan S (2012) Depressive symptoms and health-related quality of life in breast cancer survivors. J Women's Health 21:311-318. doi:10. 1089/jwh.2011.2852

16. Guo Z, Tang H, Hao L, Tan S, Feng K, Huang Y, Bu Q, Jiang W (2013) The benefits of psychosocial interventions for cancer patients undergoing radiotherapy. Health Quality Life Outcomes 11:121-121. doi:10.1186/1477-7525-11-121

17. Duffy S, Ronis D, Valenstein M, Fowler K, Lambert M, Bishop C, Terrell J (2007) Depressive symptoms, smoking, drinking, and quality of life among head and neck cancer patients. Psychosomatics 48 : 142-148. doi:10.1176/appi.psy.48.2.142

18. Sehlen S, Lenk M, Herschbach P, Aydemir U, Dellian M, Schymura B, Hollenhorst H, Dümke E (2003) Depressive symptoms during and after radiotherapy for head and neck cancer. Head Neck 25:10041018. doi:10.1002/hed.10336

19. Mikoshiba N, Miyashita M, Sakai T, Tateishi R, Koike K (2013) Depressive symptoms after treatment in hepatocellular carcinoma survivors: prevalence, determinants, and impact on health-related quality of life. Psychooncology. doi:10.1002/pon.3300

20. Aarstad HJ, Aarstad AK, Heimdal JH, Olofsson J (2005) Mood, anxiety and sense of humor in head and neck cancer patients in relation to disease stage, prognosis and quality of life. Acta Otolaryngol 125:557-565

21. Derks W, Leeuw JRJ, Hordijk GJ, Winnubst JAM (2005) Differences in coping style and locus of control between older and younger patients with head and neck cancer. Clin Otolaryngol 30:186-192. doi: 10.1111/j.1365-2273.2004.00938

22. Schou I, Ekeberg Ø, Ruland CM, Sandvik LR, Kåresen R (2004) Pessimism as a predictor of emotional morbidity one year following breast cancer surgery. Psychooncology 13:309-320. doi:10.1002/ pon. 747 
23. Karnell LH, Christensen AJ, Rosenthal EB, Magnuson JS, Funk GF (2007) Influence of social support on health-related quality of life outcomes in head and neck cancer. Head Neck 29:143-146. doi:10. 1002/hed.20501

24. Verdonck-de Leeuw IM, Eerenstein S, van der Linden MH, Kuik D, de Bree R, Leemans CR (2007) Distress in spouses and patients after treatment for head and neck cancer. Laryngoscope 117:238-241. doi: 10.1097/01.mlg.0000250169.10241.58

25. Chan KY, Chan ML, Yau TC, Li CW, Cheng HW, Sham MK (2012) Quality of life for Hong Kong Chinese patients with advanced gynecological cancers in the palliative phase of care: a cross-sectional study. J Palliat Care 28:259-266

26. Lin B, Starmer H, Gourin C (2012) The relationship between depressive symptoms, quality of life, and swallowing function in head and neck cancer patients 1 year after definitive therapy. Laryngoscope 122:1518-1525. doi:10.1002/lary.23312

27. Balderson NT, Towell T (2003) The prevalence and predictors of psychological distress in men with prostate cancer who are seeking support. 8:125-134. doi: 10.1348/135910703321649114

28. Manne SL, Rubin S, Edelson M, Rosenblum N, Bergman C, Hernandez E, Carlson J, Rocereto T, Winkel G (2007) Coping and communication-enhancing intervention versus supportive counseling for women diagnosed with gynecological cancers. J Consult Clin Psychol 75:615-628. doi:10.1037/0022-006X.75.4.615

29. Scharpf J, Karnell L, Christensen A, Funk G (2009) The role of pain in head and neck cancer recurrence and survivorship. Arch Otolaryngol Head Neck 135:789-794. doi:10.1001/archoto.2009. 107

30. Shuman A, Terrell J, Light E, Wolf G, Bradford C, Chepeha D, Jiang Y, McLean S, Ghanem T, Duffy S (2012) Predictors of pain among patients with head and neck cancer. Arch Otolaryngol Head Neck 138:1147-1154. doi:10.1001/jamaoto.2013.853

31. Dupont A, Bower JE, Stanton AL, Ganz PA (2014) Cancer-related intrusive thoughts predict behavioral symptoms following breast cancer treatment. Health Psychol 33:155-163. doi:10.1037/a0031131

32. Helgeson V, Lepore S, Eton D (2006) Moderators of the benefits of psychoeducational interventions for men with prostate cancer. Health Psychol 25:348-354. doi:10.1037/0278-6133.25.3.348

33. Albrecht K, Droll H, Giesler J, Nashan D, Meiss F, Reuter K (2013) Self-efficacy for coping with cancer in melanoma patients: its association with physical fatigue and depression. Psychooncology 22: 1972-1978. doi:10.1002/pon.3238

34. van der Meulen IC, May AM, de Leeuw JRJ, Koole R, Oosterom M, Hordijk G-J, Ros WJG (2013) Long-term effect of a nurse-led psychosocial intervention on health-related quality of life in patients with head and neck cancer: a randomised controlled trial. Br J Cancer. doi: 10.1038/bjc.2013.733

35. American Psychiatric Association (2000) Diagnostic and statistical manual of mental disorders [DSM-IV-TR]. Washington, DC, American Psychiatric Association

36. Radloff LS (1977) The CES-D Scale: A self-report depression scale for research in the general population. 1:385-401. doi: http:// dx.doi.org/10.1177/014662167700100306

37. Aaronson NK, Ahmedzai S, Bergman B, Bullinger M, Cull A, Duez NJ, Filiberti A, Flechtner H, Fleishman SB, Haes JCJM, Kaasa S,
Klee M, Osoba D, Razavi D, Rofe PB, Schraub S, Sneeuw K, Sullivan M, Takeda F (1993) The European Organization for Research and Treatment of Cancer QLQ-C30: a quality-of-life instrument for use in international clinical trials in oncology. J Natl Cancer Inst 85:365-376. doi:10.1093/jnci/85.5.365

38. Bjordal K, de Graeff A, Fayers PM, Hammerlid E, van Pottelsberghe C, Curran D, Ahlner-Elmqvist M, Maher EJ, Meyza JW, Brédart A, Söderholm AL, Arraras JJ, Feine JS, Abendstein H, Morton RP, Pignon T, Huguenin P, Bottomly A, Kaasa S (2000) A 12 country field study of the EORTC QLQ-C30 (version 3.0) and the head and neck cancer specific module (EORTC QLQ-H\&N35) in head and neck patients. Eur J Cancer 36:1796-1807. doi:10.1016/S09598049(00)00186-6

39. Singer S, Arraras JI, Chie W, Fisher SE, Galalae R, Hammerlid E, Nicolatou-Galitis O, Schmalz C, Verdonck-de Leeuw I, Gamper E, Keszte J, Hofmeister D (2013) Performance of the EORTC questionnaire for the assessment of quality of life in head and neck cancer patients EORTC QLQ-H\&N35: a methodological review. Qual Life Res 22:1927-1941. doi:10.1007/s11136-012-0325-1

40. Endler NS, Rutherford A, Denisoff E (1999) Beck depression inventory: exploring its dimensionality in a nonclinical population. J Clin Psychol 55:1307-1312

41. Fournier M, De Ridder D, Bensing J (2002) Optimism and adaptation to chronic disease: the role of optimism in relation to self-care options of type 1 diabetes mellitus, rheumatoid arthritis and multiple sclerosis. Br J Health Psychol 7:409-432. doi:10.1348/ 135910702320645390

42. van Eijk LM, Kempen GI, van Sonderen FL (1994) A short scale for measuring social support in the elderly: the SSL12-I. Tijdschr Gerontol Geriatr 25:192-196

43. Riemsma RP, Rasker JJ, Taal E, Griep EN, Wouters JM, Wiegman O (1998) Fatigue in rheumatoid arthritis: the role of self-efficacy and problematic social support. Br J Rheumatol 37:1042-6

44. Cohen J (1988) Statistical power analysis for the behavioral sciences, 2nd edn. Lawrence Earlbaum Associates, Hillsdale

45. Faul F, Erdfelder E, Buchner A, Lang AG (2009) Statistical power analyses using $\mathrm{G}^{*}$ Power 3.1 : tests for correlation and regression analyses. Behavior Research Methods 41:1149-116046

46. Hayes AF (2013) Introduction to mediation, moderation, and conditional process analysis: a regression-based approach. Guilford Press, New York

47. Norman GR, Sloan JA, Wyrwich KW (2003) Interpretation of changes in health-related quality of life: the remarkable universality of half a standard deviation. Med Care 41:582-592. doi:10.1097/01.MLR. 0000062554.74615.4C

48. Pinquart M, Sörensen S (2006) Helping caregivers of persons with dementia: which interventions work and how large are their effects? Int Psychogeriatr 18:577-95. doi:10.1017/ S1041610206003462

49. Gamper EM, Groenvold M, Petersen M, Young T, Costantini A, Aaronson N, Giesinger J, Meraner V, Kemmler G, Holzner B (2014) The EORTC emotional functioning computerized adaptive test: phases I-III of a cross-cultural item bank development. Psychooncology 23:397-403. doi:10.1002/pon.3427 